\title{
Design and Fabrication of Metal Key Holders and Cufflinks as Souvenirs for Kwame Nkrumah University of Science and Technology, Kumasi, Ghana
}

\author{
Isaac Kwabena Agyei $^{1} \quad$ Dr. Joe Adu-Agyem ${ }^{2} \quad$ Dr. Peggy Ama Fenning 3 Dr. Mohammed Kwaku Baidoo ${ }^{4}$ \\ Samuel Kissi Baah ${ }^{1} \quad$ Cyril Etornam Adala ${ }^{5}$ \\ 1 .Lecturer, Department of Industrial Art, \\ Faculty of Art, College of Art and Built Environment, KNUST, UPO, Kumasi \\ 2.Senior Lecturer, Department of Educational Innovations in Science and Technology, \\ Faculty of Art, College of Art and Built Environment, KNUST, UPO, Kumasi \\ 3. Senior Lecturer, Department of Industrial Art, \\ Faculty of Art, College of Art and Built Environment, KNUST, UPO, Kumasi \\ 4.Lecturer, AsanSka College of Design and Technology, Accra \\ 5.Lecturer, Department of Industrial Art \\ Kwame Nkrumah University of Science and Technology, Kumasi, GHANA
}

\begin{abstract}
This study explored how to merge creativity in design with the Crest of KNUST to design and fabricate quality metal key holder and cufflink as souvenirs for KNUST. Based on the assumption that the various KNUST souvenirs seem to be limited in design and therefore lack creativity and variety, which limit the option of those purchasing. In executing the study, the philosophical underpinnings of the crest of KNUST was brought to bear. The study employed aesthetics and studio- based research methods under qualitative research approach to design and fabricate quality metal key holder and cufflinks to be used as souvenirs for Kwame Nkrumah University of Science and Technology. By using the Gestalt theory of design, which is concerned with the relationship between the parts and the whole of a composition, the researchers carefully select parts of the emblem of KNUST to design and fabricate a key holder and a cufflinks. Metal working techniques such as chasing and repoussé, fording and piercing were used to these souvenirs for KNUST. The researchers made use of the various tools and machinery available at the various studios of Meta T 1 Product Section of Industrial Art Department, KNUST. These included the milling studio, $4^{\text {th }}$ Year production studio where all the piercing vices, drilling machines, stakes and soldering turntable are made available and finally the forging studio where brass scraps were melted into ingot. Results of the study revealed that by adopting the fundamental processes such as idea development, forming processes, joining processes and finishing processes coupled with the fact that local metal scraps are used, underpin the argument that producing quality and professional metal souvenirs can be done here in Ghana to meet any standard elsewhere. This shows that other metal products could be produced as souvenirs for KNUST. After carefully observing some souvenirs of KNUST and other institutions of higher learning, unique designs based on the emblem of KNUST can be done.
\end{abstract}

Keywords: fabricate, Gestalt, key holder, cufflinks, souvenirs, chasing and repousse.

DOI: $10.7176 / \mathrm{ADS} / 83-01$

Publication date:July $31^{\text {st }} 2020$

\section{INTRODUCTION}

Design means the appearance of the whole or a part of a product resulting from the features of, in particular, the lines, contours, color, shape, texture or materials of the product itself or its ornamentation. According to Ford (2001), in other words define design as the way something has been made or the way the parts of something (such as a building, machine, book, etc.) are formed and arranged for a particular use, effect, etc. Scholars from different field such as artificial science, engineering innovation and management have recognized the importance of design. Despite a shared understanding of the role of design as a potential enabler of innovation, they still acknowledge a wide range of meanings. (March \& smith, 1995; Hernier et al. 2004; Potts \& Cunnigham, 2008; Potts, 2009; Walsh, 1996; Verganti, 2003). Design inspirations for producing metal key holder and cufflink were taken from the Crest of Kwame Nkrumah University of Science and Technology (KNUST) in line with the interpretational guidelines.

It is a generally accepted belief that metal was discovered before people began to write and was first used to make tools and weapons such as arrowheads. Metal fabrication processes and techniques are also scientifically referred to as metallurgy (Marcoe, 2003). Many historians, anthropologists, ethnologists and researchers such as Gerrard (1980) have talked about metal works in various intellects and dimensions. Metalwork embraces a wide area of profession; some of which include blacksmithing, goldsmithing, silversmithing, casting, welding, jewellery fabrication and many others (Holl, 2000). All these professions come along with its working processes called metalworking. Metalworking is the process of using metals to fabricate and create functional items called 
metal works. The term covers a wide range of metalwork from large items to be precisely small and delicate jewellery work (Tetteh \& Adu-Agyem, 2014). It therefore includes a correspondingly wide range of skills, techniques and processes needed for this project. In expressing his view on metalworking processes, McCreight (1991) opines that the emphasis is on how technical insight of metal manipulation can lead to forging metals into desired shapes to serve many purposes in our environment. That is specifically the point that this research is sought to make designs and fabricate some metal key holder and cufflinks as a souvenirs to rebrand KNUST. Schey (1997) defines fabrication process as the ability of a metal to be fabricated by various manufacturing processes such as formability, workability, castability, forgeability, machinability and weldability. Schey in his definition uses techniques in fabricating metal to elucidate what metal processes is all about. It is wealthy to note that Schey's definition underpins some of the processes that the researchers used in producing these souvenirs for the KNUST.

Industries such as jewellery arts and crafts as well as technological areas are mostly where metal fabrications are used. Tammy (2012) describes fabrication as when using metal materials such as metal plate and wire for where you use methods such as sawing, filing, and hammering to reform the metal piece the purposes of jewellery making, very often the jewellery maker is required to shape and form the metal. The techniques used to do this are considered fabrication techniques into a different structure and shape. Fabrication, therefore, is different from other types of metal techniques such as casting where you might have some kind of mould and you pour the hot metal into the mould to create the structure you need for a jewellery piece. With fabrication, you use hand tools, some finesse, and a little elbow grease to come up with the desired results.

Tammy also stated that while casting and soldering may get all the glory when it comes to metalsmithing, neither is really possible without first learning how to fabricate metal. In fact, you cannot really do soldering without also doing at least a little fabrication. For example, you may cast a metal charm, but you still need to file off the rough parts and polish the finished piece. You may need to solder two pieces of metal together, but unless the metal has been cut, filed, and cleaned properly, you will not have soldering success. To sum it up, the researchers are of the opinion that fabrication is when a particular form of metal is transformed, manipulated or changed into another form. Gordon (1986) defined souvenirs as some specific objects that reminded certain incident or journey. The existence of souvenirs could help visitors explore definition and stay in contact with a travel experience not long ago, and tourists purchase souvenirs as a proof of the places they had visited. Swanson and Horridge (2006) thought souvenirs were specific objects that served as reminders of a special event or memory, and this included post cards, T-shits, and local crafts.

Kwame Nkrumah University of science and Technology just as any other specialized organization has been commission people to produce various souvenirs for them. It is a challenge that despite the existence of some souvenirs, little account of metal souvenirs for KNUST with unique and philosophical basis can be found among the various souvenirs. Although, there are metal scraps available metal designers and fabricators producing other metalwork souvenirs with high aesthetic values have not looked at producing metal souvenirs for KNUST. In this respect, the researchers explore how to merge creativity in design with the Crest of KNUST to design and fabricate quality metal key holder and cufflink as souvenirs for KNUST. Based on the assumption that the various KNUST souvenirs seem to be limited in design and therefore lack creativity and variety, which limit the option of those purchasing.

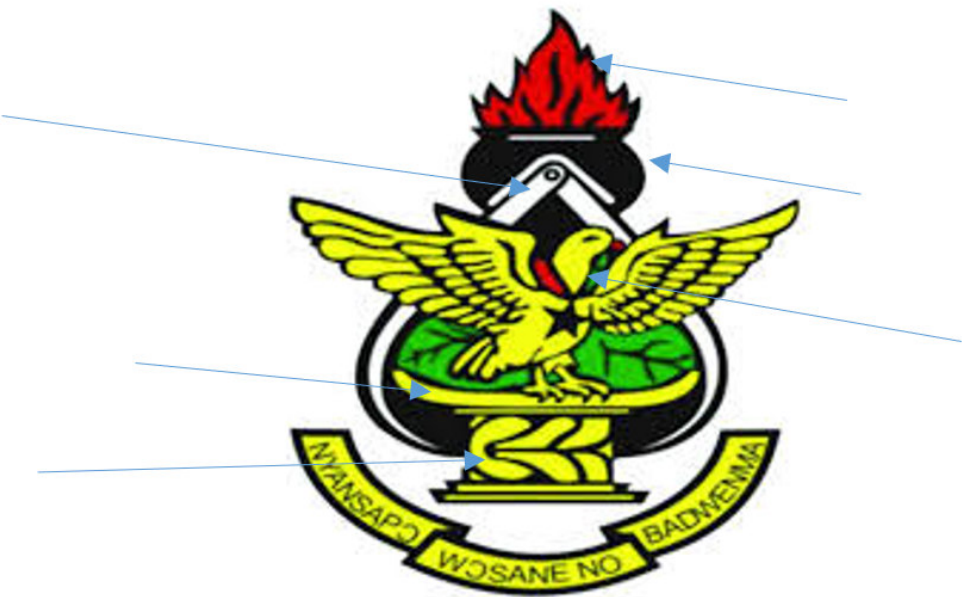

Figure 1: Crest of KNUST

The motif and philosophy behind the designing and producing metal key holder and cufflinks as souvenirs of KNUST take its root from the crest of the university as seen in plate 1. The crest is made-up of different items that have composed artistically. The Pot signifies the storehouse of knowledge. The flame represents the quest for 
knowledge which should be kept alive and burning always. The Calipers is a tool which is used by a cross-section of scientists and technologists, represents science and technology as the foundation or the cornerstone of the development and progress of the country. The Stool symbolizes the fact that the University is the highest level of the educational ladder. It also signifies the University's authority in science and technology in Ghana and beyond. The Nyansapo (Knot of Wisdom) this underscores the University's status as the repository of knowledge and wisdom for untying intricate knots of problems. The Eagle is the king of all birds. It soars gracefully higher and faster than other birds and are endowed with keen eyesight. It signifies the fact that the University has a wider and clearer understanding of the many problems confronting the country and the capacity to solve them effectively and efficiently.

\section{MATERIALS AND METHODS}

A study into the production of metal key holders and cufflinks as souvenirs for Kwame Nkrumah University of Science and Technology reflects in the group of activities that require investigation techniques into design and fabrication concepts to reach at concrete results. It is therefore imperative to apply a well-defined and systematic methodology for achieving authentic results. In this regard, Aesthetic-Based and Studio-Based research methods beneath the qualitative research designs were employed for the study. Best (2003) opines that qualitative research is usually based on quality rather than quantity According to Leedy and Ormrod (2005) qualitative research study is relevant for the purpose of description, interpretation, verification and evaluation of situations, settings, processes, relationships, systems or people. This method was chosen because as regards the designs and the fabrication of metal key holder and cufflinks as souvenirs for KNUST, quality is paramount and need not to be compromised. In another vain, Given (2008) postulates that aesthetic-based research refers to qualitative inquiry that focuses on philosophical concepts and considerations of the arts and of aesthetic experiences of the subject. Stecker (2010) articulates aesthetic-based research as a study of new ways of seeing, appreciating and perceiving the world. Similarly, Danto's (2004) explanation is that aesthetic-based research expresses a process of research concerned with the principle, perception and insight of beauty and ugliness in relation to the question of whether such qualities are objectively present in the things they appear to qualify, or they exist only in the mind of the individual.

Aesthetic based research was relevant to the study because souvenirs for that matter for KNUST are meant to project and brand the image of the institution and therefore had to be carefully designed and produced for it to be aesthetically pleasing to users and people alike. Based upon the crest of KNUT, designs were carefully made to attract people to patronize them. Again, the production processes were also carefully chosen to aid the beauty of the works. Surface decorative methods were also employed to make produced works look more aesthetically pleasing.

The other research method that was used in the study was studio-based research practice. A studio-based research involves the production of artworks. The imaginative and intellectual undertaken by artists are considered to be forms of research and they are evaluated on these five factors.

1. Description of the subject matter of the artefact produced

2. Identification of iconography

3. Notation on impact of selected media and methods of production.

4. Principles of art and organization of visual elements, such as line, color, space, movement, time and composition.

5. Description of styles or processes (Marshal, 2010).

The requirements of a studio-based research were achieved by making use of the various tools and machinery available at the various studios, which included the milling studio, $4^{\text {th }}$ Year production studio where all the piercing vices, drilling machines, stakes and soldering turn table are made available and finally the forging studio where brass scraps were melted into ingot.

Tools, materials and equipment

In every practically oriented study, the tools, materials and method used are paramount, since the end product is supposed to be a tangible artefact. In this regard, the researchers present in table 1 some of the tools, materials and equipment used in the research. 
Table 1: Tools, equipment and materials used and their purposes.

\begin{tabular}{|c|c|}
\hline Tools & Purpose \\
\hline Soldering Board & Heat and crack resistant board on which effective soldering is done. \\
\hline Chasing tools & $\begin{array}{l}\text { Hand held steel tools with varying shapes used to create a relief effect on metals. } \\
\text { The chasing tools were used in the production of the mug and cufflinks. }\end{array}$ \\
\hline Pliers & $\begin{array}{l}\text { Used in forming, coiling and holding pieces of metals in place at various stages of } \\
\text { production. }\end{array}$ \\
\hline Shears & For cutting small pieces of metal and solder \\
\hline Tweezers & $\begin{array}{l}\text { For picking and placing pieces of solder and for picking hot pieces of metal after } \\
\text { soldering or annealing. }\end{array}$ \\
\hline Saw frame and blades & For piercing or cutting pieces of metals \\
\hline Files & $\begin{array}{l}\text { For filing, smoothening and rounding the edges of the works produced to make them } \\
\text { look presentable. }\end{array}$ \\
\hline Emery Papers & $\begin{array}{l}\text { A variety of emery papers, ranging from grade } 320 \mathrm{~m} \text { to } 1200 \text { were used in polishing } \\
\text { the works to mirror finish. }\end{array}$ \\
\hline Rule & For taking accurate measurements \\
\hline Pencil & For making out points to be pierced \\
\hline Pitch & Holds and supports metals for chasing and repoussé. \\
\hline Sand Paper & For levelling the metal for easy soldering \\
\hline Clamp & Used for holding the mug in position during raising a d chasing \\
\hline Stakes & For the forming of vessels and containers of varying shapes and sizes like the mug \\
\hline Rouge and Tripoli & Used to facilitate polishing \\
\hline Torch & For soldering and annealing metals \\
\hline Ring plier & For bending and coiling of metals \\
\hline Equipment & Purpose \\
\hline Rolling Mill & Used in drawing metals into sheet or wires with varying thickness \\
\hline Guillotine Machine & For cutting stripes of metals \\
\hline Polishing Machine & For polishing metals \\
\hline Flexi shaft & Used in conjunction with burs and bits to drill, set stones and polish metals. \\
\hline Materials & Purpose \\
\hline $\begin{array}{l}\text { Sheet Metal( Copper, } \\
\text { Brass, Silver) }\end{array}$ & $\begin{array}{l}\text { The various metals were used in producing the varying types of souvenirs. Copper } \\
\text { and brass were used in producing the key holder and the silver was used in producing } \\
\text { the cufflinks }\end{array}$ \\
\hline Solder & Soft solder was used to join the pieces of metals together. \\
\hline Borax/flux & $\begin{array}{l}\text { It is a flowing agent that facilitates soldering and melting by removing oxidation from } \\
\text { the metals to be joined. }\end{array}$ \\
\hline
\end{tabular}

\section{Design Processes}

\section{Concept and idea development for Key holder}

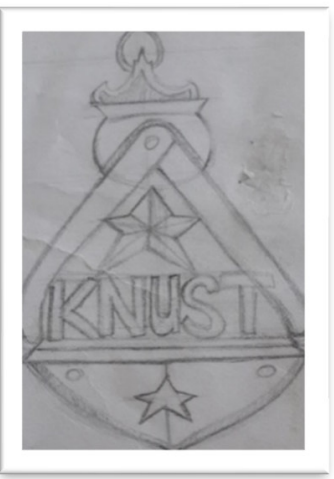

Fig 1 Sketch 1

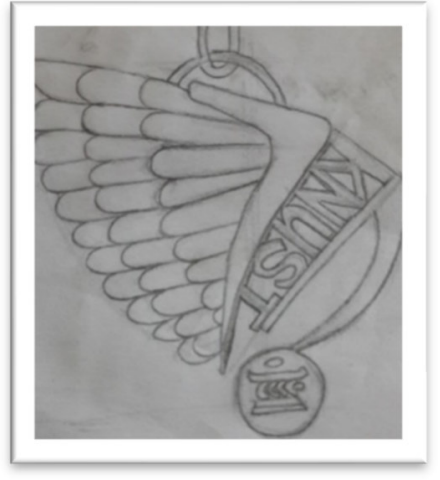

Fig 2 Sketch 2

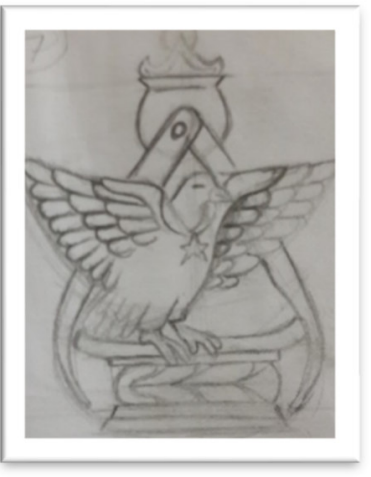

Fig 3 Sketch 3

Figure 1 sketch 1 shows a key holder incorporating the pot of fire at the top of the opened calipers with 2 stars (one at the center and the other at the bottom) with KNUST boldly written between the two stars. Figure 2 sketch 2 is another key holder which is mainly designed with the wings of the eagle spread on one side of the key holder and a bold lettering of KNUST on the other side with the Nyansapo stool dangling below on a circular disc. Figure 3 is another sketch displaying the full image of the eagle with its wings spread apart, standing on the 
Nyansapo stool with the pot of fire and calipers behind it.

\section{Concept and idea development for Cufflinks}

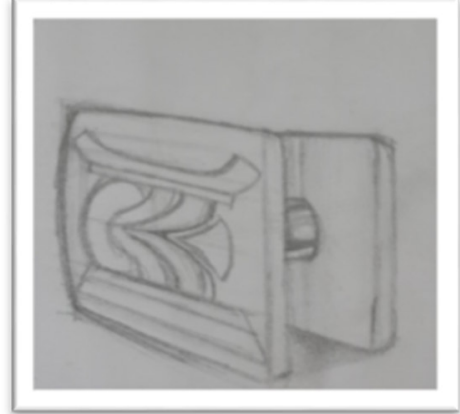

Fig 4 Sketch 1

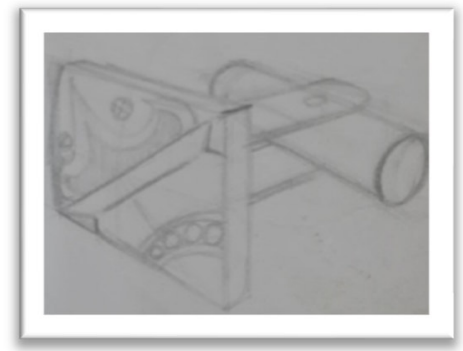

Fig 7 Sketch 4

A total of six

(Figures 4 Sketch

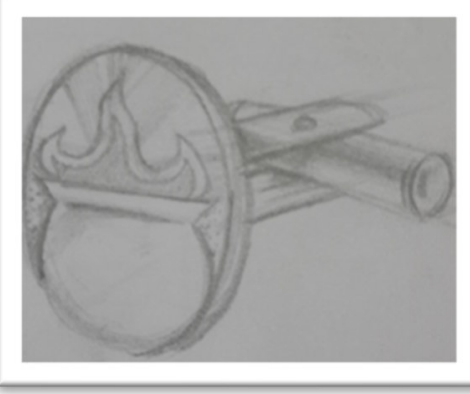

Fig 5 Sketch 2

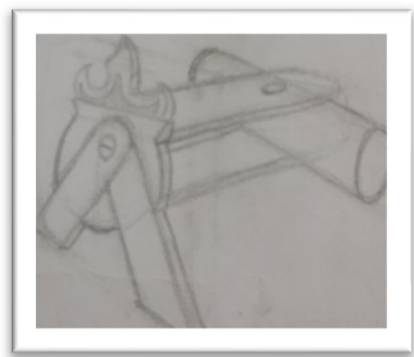

Fig 8 Sketch 5

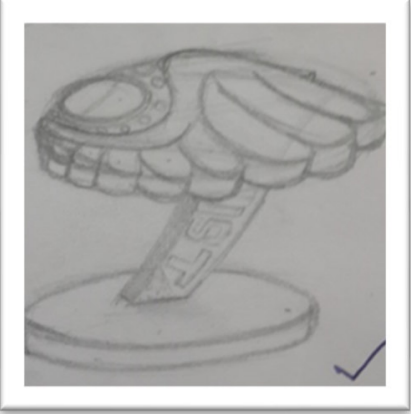

Fig 6 Sketch 3

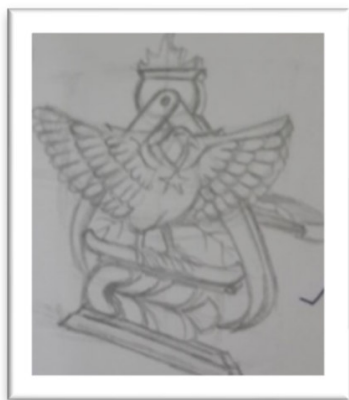

Fig 9 Sketch 6 the image of the university and function as a souvenirs were made. This cufflink incorporates the Nyansapo stool on a rectangular base as showed in Fig. 4 sketch 1. Fig 5 sketch 2 also displays a circular base on which the pot of fire has been placed. Fig. 6 sketch 3 incorporates the wings of the eagle, with half-moon arrangement of drilled holes and a tube set gemstone. Fig. 7 sketch 4 also shows a rectangular base with the pot of fire diagonally placed in the right bottom corner, in between the flames are two gypsy set gems and 4 drilled holes at the bottom of the pot. The fifth cufflink Fig. 8 Sketch 5 is simply the pot of fire with half the cufflinks placed in the middle. The final design Fig 9 sketch 6 is a cufflink made of the entire elements of the KNUST logo which is the eagle, the calipers the nyansapo stool and the pot of fire.

Figures 3 sketch 3 and Figure 9 sketch 6 according to artists and respondents give a true reflection of the University's logo for that matter were selected over the rest as key holder and cufflinks accordingly.

\section{Fabrication Processes: Key Holder and Cufflinks}

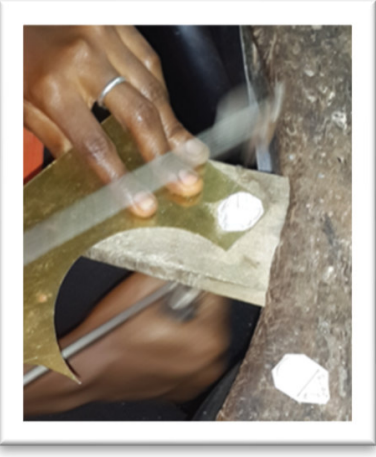

Fig. 10 Piercing of parts

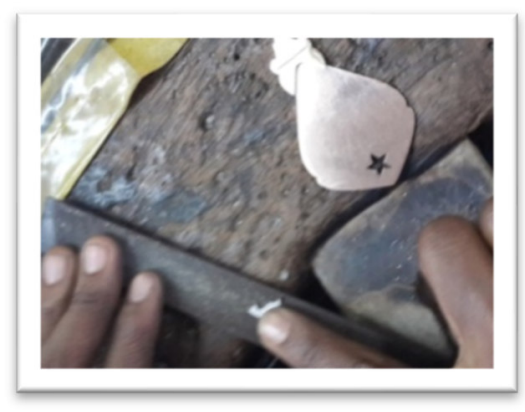

Fig. 11 Filing and Polishing

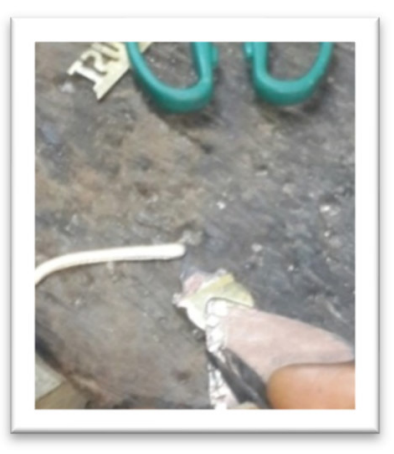

Fig. 12 Placing of Solder 


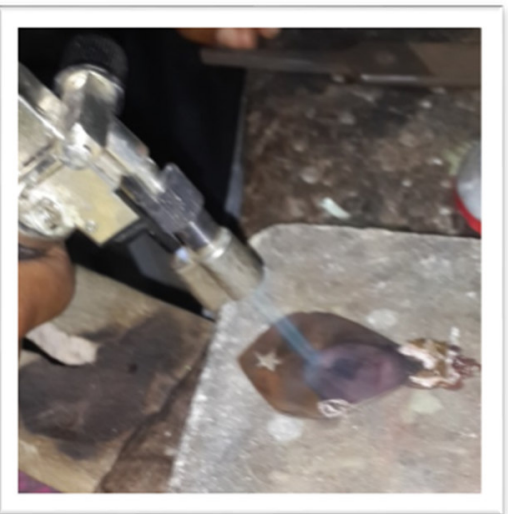

Fig 13 Soldering

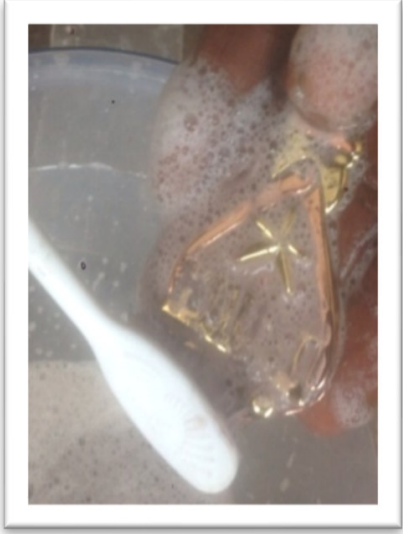

Fig. 16 Washing

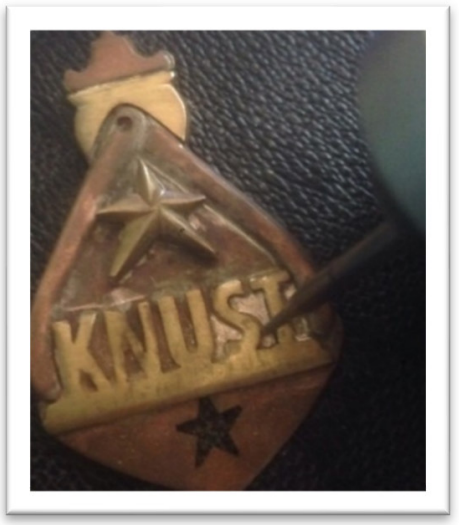

Fig. 14 Texturing

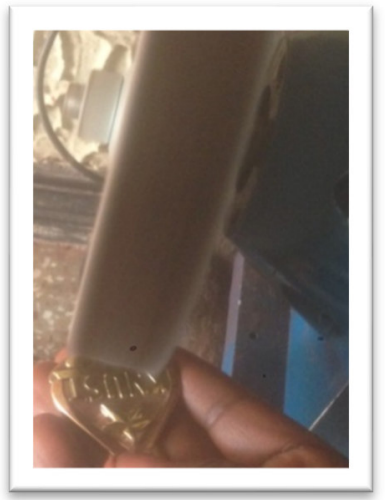

Fig. 15 Polishing

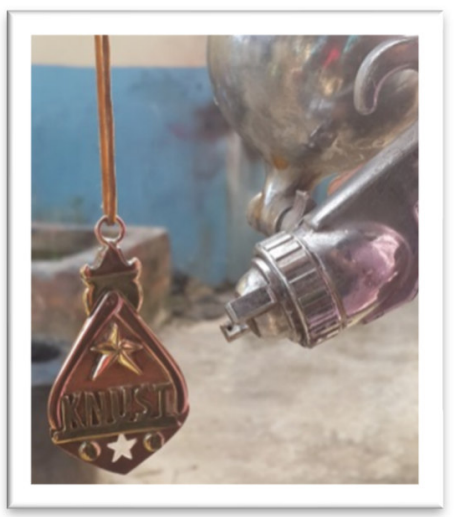

Fig. 17 Lacquering

Figure 10 to Figure 17 show the fabrication processes of the Key holder as souvenir for Kwame Nkrumah University of Science and Technology. The fabrication process commenced with cutting or piercing of all parts to sizes as shown in figure 10. Prior to soldering activity, all parts were polished to remove all dirt and carbon so that soldering could easily be done as shown in figure 11 . Some of the pierced parts which would be difficult to polish well to luster were all filed and polished first before soldering the join the parts together. Before soldering the parts together, solder put in borax or fluxing agent were carefully placed at the joints as seen in figure 12. Figure 13 shows the actual soldering process where the solders placed at appropriates parts were heated to flow at the joints to join the parts together to make a whole work. Parts which were very difficult to access were textured accordingly as seen in figure 14. This was also a finishing technique which was done to improve the beauty of the work. Figure 15 also depicts the actual polishing process where polishing compounds such as rouge and Tripoli were used to achieve shiny surface of the work after emery papers of different grades were used. After polishing with the polishing compounds, some of these compounds are normally trapped in certain parts of the works which need to be removed either through brushing under running water (fig.16) or using ultrasonic cleaner. In other to expose the work to atmospheric temperatures to tarnish the surface of the work, lacquer was applied unto the surface of the work as seen in fig. 17

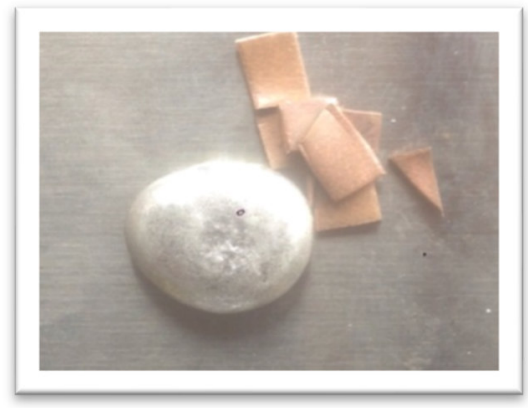

Fig. 18 Preparation of Silver

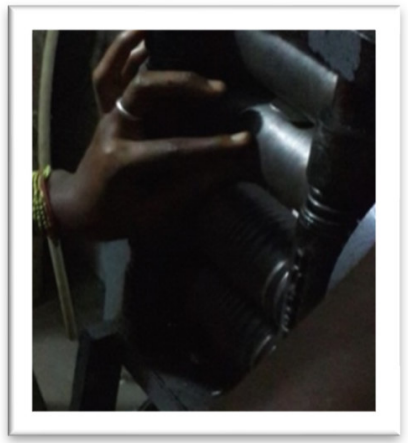

Fig. 19 Milling of silver 


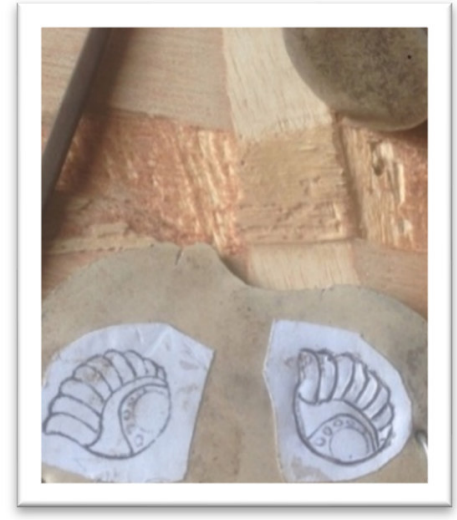

Fig.20 Pasting of designs to cut

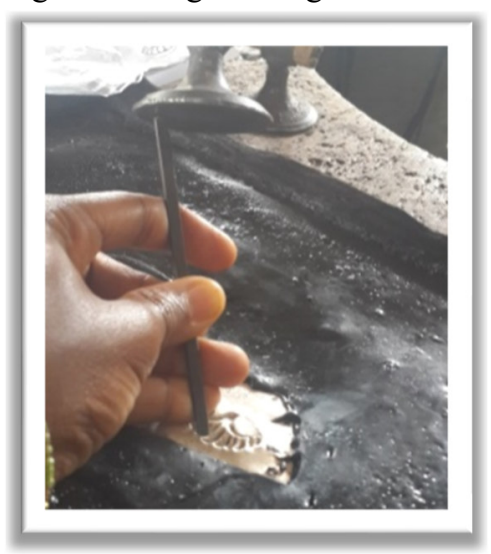

Fig. 22 Chasing and Repoussé

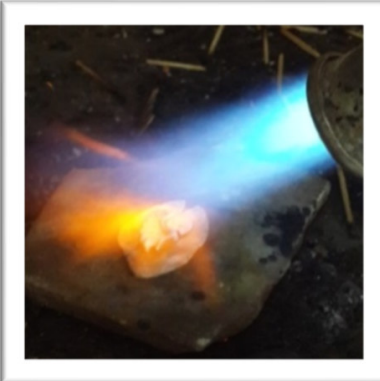

Fig. 24 Soldering to Base

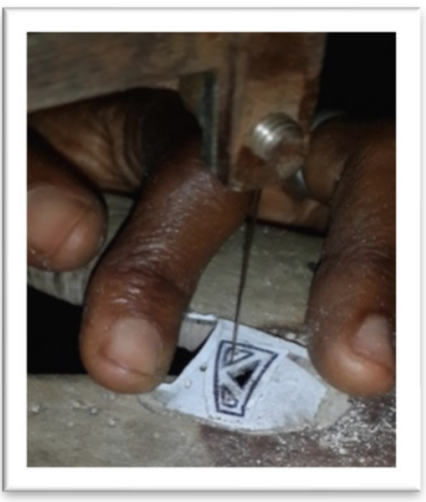

Fig.26 cutting of locking mechanism

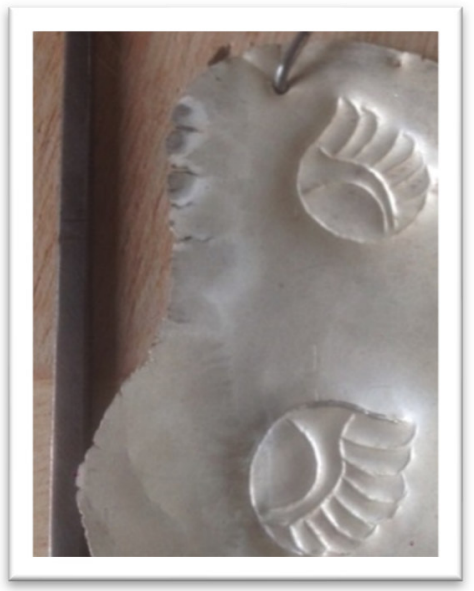

Fig. 21 Tracing of Design

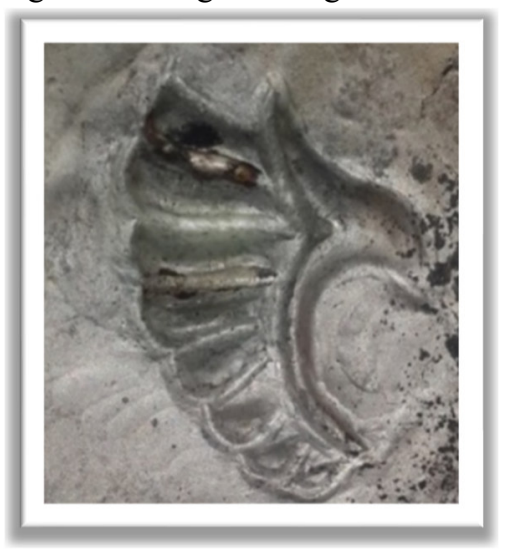

Fig. 23 Outcome of chasing and repousse

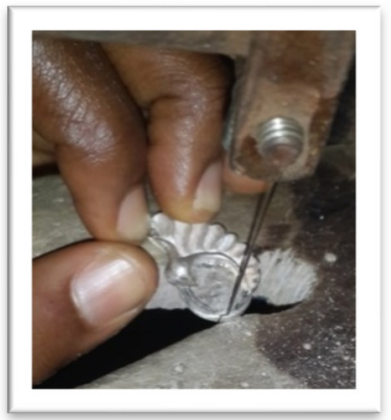

Fig 25. Piercing design out from the base

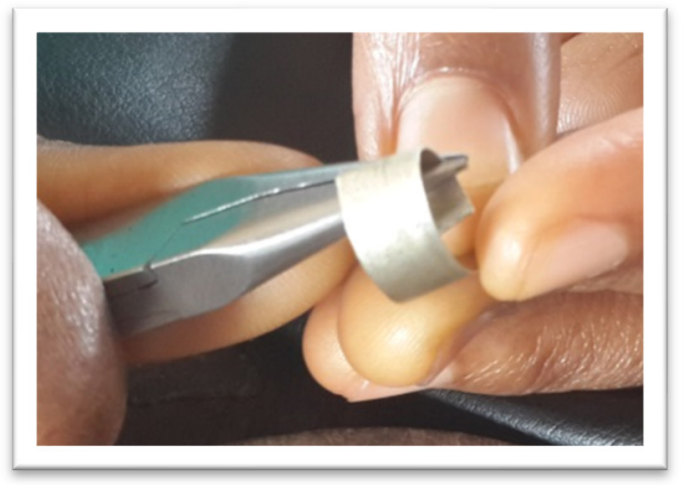

Fig 27 cutting of tube for gem setting 


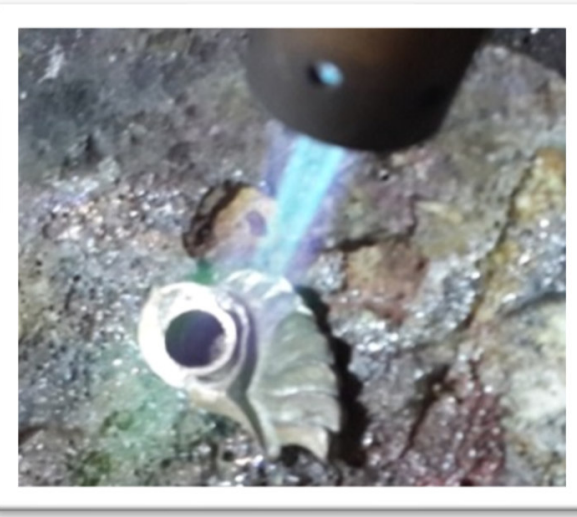

Fig. 28 Soldering of ring for stone setting

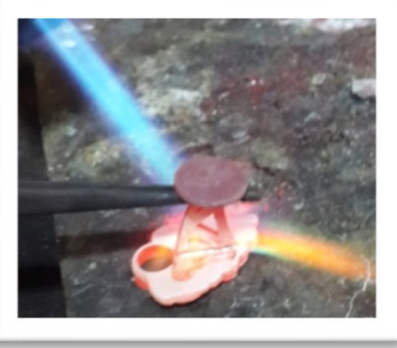

Fig. 30 Soldering of the locking mechanism

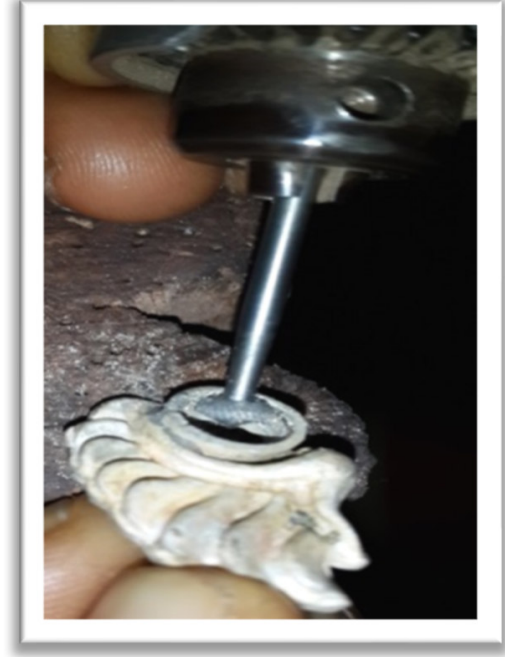

Fig.29 Cutting of the seat for stone setting

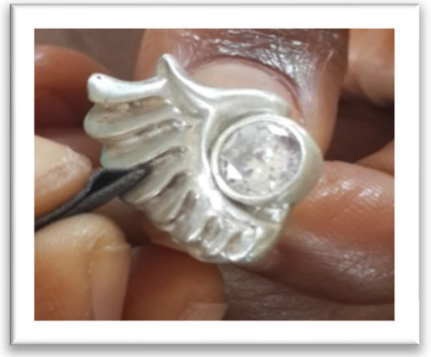

Fig.31 Polishing of work

Figures 18-31 describes the process of fabricating the cufflinks as souvenir for KNUST. The silver as in fig. 18 was prepared by alloying the pure silver to sterling which 925 which comprises $92.5 \%$ pure silver and 7.5 copper. After the preparation of the silver and alloying, the silver had to be milled to get it flat for the commencement of cutting and the rest as seen in fig 19. The actual design made in corel draw was place onto the milled flat sheet to be pasted and traced accordingly (fig 20 and 21). After tracing the work onto the sheet, the outline was traced and placed onto alsphatum pitch and properly chased and repousséd (fig.22) and with the outcome seen in fig. 23. The chased work was then soldered to a metal base and then outline pierced accordingly (fig. 24 and 25). Cutting of the locking mechanism for the cufflinks and the tube for the setting of the gem stone were done respectively (fig. 26 and 27). The cut ring was later soldered to the cufflinks and seat cut to make ready for the gem setting respectively (Figures 28 and 29). After cutting of the seat for the gem stone, the locking mechanism was then soldered to the back of the cufflinks (fig 30). Stone setting was done and work polished as shown in fig. 31 .

\section{RESULTS AND DISCUSSION}

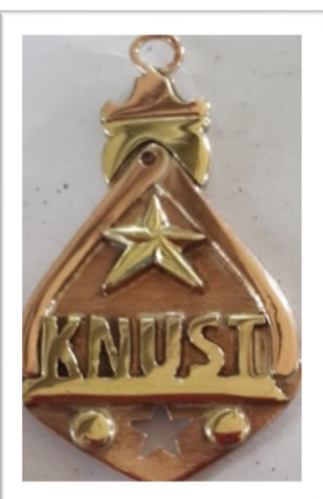

Fig. 32 final key holder

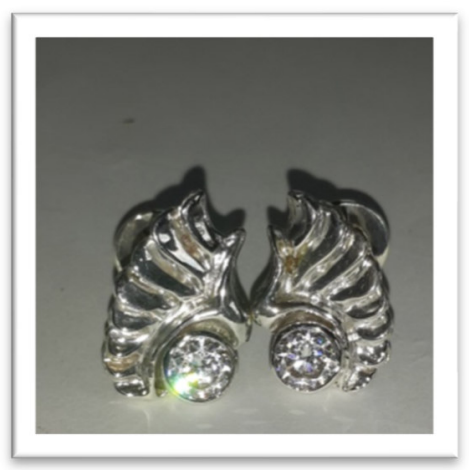

Fig. 33 final cufflinks

Figures 32 and 33 is the final outcome of the designs and the fabrication processes for the key holder and the 
cufflinks respectively. Metal souvenirs in general are not new to this world, a wide variety of such souvenirs exist in many shapes and designs all over this country and in this world but these specific souvenir was made to suit KNUST as a school for unique representation purposes.

The choice of material for this particular work (fig 32) was a combination of copper and brass for durability and beauty. It measures $2.5 \times 1.5$ " and has an approximate thickness of $2.84 \mathrm{~mm}$. The techniques employed in its fabrication were piercing and soldering. After piercing and soldering, the work was finished by texturing, filing, and polishing for even more beauty. The execution of the work was to serve the purpose of a key holder suitable as a souvenir for KNUST. It is made up of a combination of elements present in the KNUST logo, designed to produce a unique design suitable as a key holder. At the very tip of the key holder is the pot of fire with the open caliper placed right below it. Calipers in the design also represents the technological disciplines in the University being Science and Technology Institution of higher learning In between the open caliper are a star and a bold KNUST inscription. That specific design was chosen for the key holder because it was best suited for the purpose and its shape and size makes easy to be carried in the pocket or hand of the carrier. Therefore, its size, shape and highly, polished finishing make it both portable and attractive and all the pieces were carefully soldered to ensure durability.

Cufflinks (fig. 33) is a jewellery consisting of a pair of linked buttons used to fasten the cuffs of a shirt. Since cufflinks are jewellery/accessories, sterling silver was the material of choice. The entire piece measured 1x 0.7 " with a thickness of $2.46 \mathrm{~mm}$. Chasing and repousse were the techniques employed in the fabrication of the main body, whilst piercing was used for the mechanism at the bottom and all the parts were joined by soldering. After fabrication the work was filed, and polished to give a lustrous shine. The cufflink is mainly made up of the wings of the KNUST eagle. Only a single element of the, logo was used in its designing because cufflinks are relatively small and more than one element would have made it look over crowded and clumsy. At the edge of the wings is an arrangement of drilled holes and tube set cubic zirconia. The design and techniques of fabrication all summed up to give a simple yet classy look.

\section{Findings on material, tools and method of production of the metal souvenirs.}

The main materials used for the production of these metal souvenirs for KNUST were Copper, Brass, Silver, alsphatum and pickle solution. Copper is a chemical element with the symbol $\mathrm{Cu}$ (from Latin: cuprum) and atomic number 29. It is a soft, malleable, and ductile metal with very high thermal and electrical conductivity. A freshly exposed surface of pure copper has a pinkish-orange color. Copper is the predominant material used in the production of the key holder. The researcher's findings reviewed a lot of advantages and disadvantages in the usage of the material for the production of the key holder as metal souvenir.

The softness of copper partly explains its high electrical conductivity $\left(59.6 \times 10^{6} \mathrm{~S} / \mathrm{m}\right)$ and high thermal conductivity, second highest (second only to silver) among pure metals at room temperature. Copper is very soft and can easily be manipulated to make any shape of a choice. This feature helped file, twist, turn and milled the sheet to any favourable choice to aid in the production of the works. Breakages were not seen using copper to produce these trophies. Another observation is the fact that it was also ductile in nature. Because copper melts at a very high temperature, the possibility of melting the works in the process of soldering was minimal. Again, copper gives a very strong bond when soldered together because of its high melting temperature feature. Some findings on the disadvantages is that, there was skin itching and irritation when the skin came into contact with the copper filings. It made finishing on time very difficult. Another observable factor too was that after polishing and when the work was exposed to atmospheric temperature, the work began tarnishing. This necessitated the need to lacquer and oxidize the works to avoid that. This also called for an extra cost on the production of the work. Some of the copper used were scraps. Melting copper scraps became very difficult because of its high melting temperatures.

Silver was also a very important material used in the production of the cufflinks as souvenir for KNUST. Silver is a precious metal as very expensive as compared to copper and brass and very cheap as compared to gold. Silver is a chemical element with the symbol $\mathrm{Ag}$ (from the Latin argentum, derived from the Proto-Indo-European $\mathrm{h}_{2}$ erǵ: "shiny" or "white") and atomic number 47. As a soft, white, lustrous transition metal, it exhibits the highest electrical conductivity, thermal conductivity, and reflectivity of any metal. Silver is very malleable and more workable in the production of the selected metal souvenirs for KNUST. After polishing, it gave a nice greyish and whitish lustre which makes the works very attractive and aesthetically pleasing. There was no tarnishing of the surface of the polished silver as compared to copper. Another finding which was very advantageous was the fact that silver solder which was used in all soldering activities was not seen at the soldered joint unlike in brass and copper which was more visible. This is because silver has the same colour as the solders used for the production of these metal souvenirs.

Another material used in the production is called alsphatum, which is a black substance used in chasing and repousse. This was used in place of bee wax as a platform for chasing so that the metal should will not dent and bend haphazardly. The mixture of the alsphatum with turpentine makes it take a little longer before drying for the 
chasing to be done on the works that needed chasing. Dirt was prevalent in the chased works and needed a lot of time to clean them. Pickle solution which is made up of one part of hydrochloric acid plus 8 parts of water was very efficient in the removal of oxidation and dirt after annealing and soldering processes. This practically helped in seeing all parts of the work to know areas which need more attention. It also helped the work to be clean and neat. The only disadvantage observed is that the solution gets dirty easily and more pickle solution had to be prepared therefore calling for extra cost to buy more acid to prepare a pickle solution.

Milling machine was also prevalent as silver metal had to be milled to a sheet to produce the metal souvenir of cufflinks for KNUST. The milling machine used had some problems on the rollers and it was also only the milling machine at my disposal. This created a lot of dents on the copper sheets which used a lot of hours to remove them by filling and using emery papers of different grades. Some parts of the rollers were corroded as a result of an exposure of nitric acid. As a result, the rollers could not help get even surfaces of the milled metals. Observations and findings on the metal working techniques used were very successful with little surmountable challenges. The predominant metal working technique used is piercing. This technique was used in all the productions of the metal souvenirs. All parts needed to be cut were cut accordingly. Since cutting needed saw frame and blades, the advantages and the disadvantages earlier discussed is applicable. Without this technique, works would not have been produced. Another technique is soldering which is joining of metal parts together by silver solder. The silver solder used were prepared in three different forms such as easy, medium and hard solders. More of hard solder was prepared and used since it brought about strong bonding and helped in subsequent soldering with medium solder. The technique of lacquering and oxidizing was very efficient in preventing corrosion as a result of atmospheric temperature exposures.

\section{Conclusions}

The researchers in this study explored how to merge creativity in design with the Crest of KNUST to design and fabricate quality metal key holder and cufflink as souvenirs for KNUST. Based on the assumption that the various KNUST souvenirs seem to be limited in design and therefore lack creativity and variety, which limit the option of those purchasing. In executing the study, the philosophical underpinnings of the crest of KNUST was brought to bear.

The fundamental processes such as idea development, forming processes, joining processes and finishing processes that characterized this study coupled with the fact that local metal scraps were used, underpin the argument that such quality and professional metal souvenirs can be produced here in Ghana to meet any standard elsewhere. The study has also shown that is possible to use the crest of an institution for identification purposes to design and produce works which can help market the institution far aside any means of marketing the universities.

Aesthetic qualities were philosophically exhibited through the use of principles of design and elements of art in this study. Dynamically, the researcher did his own designs before production and in these drawings, he used lines, dots, shapes, colors and textures to explore the collective identity KNUST as imbedded in the logo. This trend gave insight into the unique aesthetic values and expressions of the philosophies of KNUST.

\section{References}

Adu-Agyem, J. (1990). Concept of aesthetics, appreciation and criticism among indigenous Asante carvers. Master's thesis submitted to the University of Science and Technology, Kumasi, Ghana. p.6

Best, J. W. (2003). Research in education. Englewood Cliffs, New Jersey: Prentice Hall Inc.,

Danto, A.C. (2004). The transformation of the Commonplace. A philosophical perception of art. Athens, Greece: Metaixmio Publication. p. 14

Davis, P. (2007). Systematic reviews in the social sciences: A practical guide. Blackwell Pub.

Descriptive Research (2008). Descriptive research. Accessed from http://www.phac-aspc.gc.ca/publicat/cdicmcc/18-3/d_e.html [accessed March 23, 2018]

Ford, T. (2001). Design innitiative. Johanisberg: J.J Publications

Garrard, T.F. (1980). Akan weights and the gold trade. London, UK: Prentice Hall Press.

Gill, P., Stewart, K., Treasure, E., and Chadwick, B. (2008). Methods of data collection in qualitative research: interviews and focus groups. British dental journal, 204(6), 291-295.

Given, L.M. (2008). The SAGA encyclopaedia of qualitative research methods. Volume 1and2. New York, U.S.A: Sage Publications, Inc. p. 63

Gordon, B. (1986). The souvenir: Messenger of the extraordinary. Journal of Popular Culture, 20(3), 135-146.

Hein, H. and Korsmeyer, C. (1993). Aesthetics in feminist perspective. Indianapolis, USA: Indiana University Press. p. 20

Hernia, A., O’Donovan, P., Agarwala, A., and Hertzmann, A. (2004). Usage of Artificial Intelligence in Today's Graphic Design. Online Journal of Art and Design, 6(4), 183-198

Holl, A.F.C. (2000). Metal and precolonial African society. Walnut Creek, California, USA: Altamira Press. p.3 Kaplan, B., and Maxwell, J.A. (2006). Qualitative research methods for evaluating computer information systems, 
In: Evaluating the Organisational Impact of Healthcare Information Systems (2nd Ed.). New York: Springer. Leedy, D.P. (1981): Practical research planning and design. New York: McGraw Hill Inc. pp79-80

Leedy, P.D. and Ormond, J.E (2005). Practical research. Planning and design (8 ${ }^{\text {th }}$ Edition). New Jersey, USA: Pearson Prentice Hall Publications.pp.87-90

Marcoe, M. (2003). Metal fabrication. History of metal fabrication. New York Academic Press, pp. 56, 57

Marc, S.T. and Smith, G.F. (1995). Design and natural science research on information technology. Decision Support Systems, 15 (1995)251-266

Marshall, C. (2010). A research design for studio-based research in art, Teaching Artist Journal, 8(2), 77-87

McCreight, T. (1991). The complete metalsmith: An illustrated handbook (Revised Edition). Massachusetts, USA: Davis Publications, Inc. pp. 5, 55-71

Petroski, H. (1996). Invention by Design: How Engineers Get from Thought to Thing, Harvard University Press, Cambridge

Potts, J. (2009). Why the creative industries matter to economic evolution. Economics of Innovation and New Technology, 18(7-8), 633-674

Potts, J. and Cunningham, S. (2008). Four models of the creative industries. International Journal of Cultural Policy, 14(3), 233-248

Schey, J.A (1997). Manufacturing processes and their selection, materials selection and design. ASM Handbook Vol 20, ASM, pp. 694

Stecker, R. (2010). Aesthetics and the philosophy of art: An Introduction (2 ${ }^{\text {nd }}$ Edition). Plymouth, United Kingdom; Row man and Littlefield Publishers, Inc. p. 4-5

Simon, H. (1996). The sciences of the artificial. Cambridge, Mass.: MIT Press.

Swanson, K.K., \& Horridge, P.E. (2006). Travel motivations as souvenir purchase indicators. Tourism Management, 27(4), 671-683

Tammy, P. (2012). What is fabrication? Scientific reports, 8 (1), 113-122

Tetteh, N.A. and Adu-Agyem, J. (2014). Symbolic and aesthetical implications of precious metals in Ghana: The perspective of Akan Culture. International Journal of Innovative Research and Development. 3(2), 49-55

Verganti, R., 2003. Design as brokering of languages: innovation strategies in Italian firms. Des. Manag. J. 14, $34-42$

Wah, S.S. (2013). Wise leadership: Timeless wisdom from the ancient Chinese. Singapore, Bookbaby Print Services.p.16.

Walsh, V. (1996). Design, innovation and the boundaries of the firm. Res. Policy, 25, 509-529. 